\title{
A Partnership for Creating Successful Partnerships
}

W hen Marc asked me to write this column I eagerly accepted because I feel strongly about libraries leveraging their role to their greater advantage in the rapidly changing information landscape. I see sponsorships and partnerships as an important tool for doing that. However, as noted in Marc's column in this issue, we'd been having a discussion about the continuing involvement of Ex Libris in the LITA/Ex Libris Student Writing Award. Like many of you, we at Ex Libris are trying to keep our costs low in this challenging economic environment so that we can in turn keep your costs low. Thus we are closely evaluating all expenditures to ensure their cost is justified by the value they return to our organization. I won't repeat the discussion already outlined by Marc above, but will just note with great pleasure his willingness to not only listen to my concerns, but to try and address them. His invitation to write this column was part of that response, a chance for me to share my thoughts and concerns with you about sponsorships and partnerships and where they need to go in the future.

To do that, I'd like to expand on some of the concepts Marc and I were discussing and talk about how to make sponsorships and partnerships successful. I want to look at what successful ones consist of as well as what types are needed in our profession tomorrow.

\section{The elements of successful sponsorships and partnerships}

For a sponsorship or partnership to be successful in today's environment, it should offer at least the following components:

1. Clear and shared goals. Agreeing what is to be achieved via the sponsorship or partnership is essential. Furthermore, it should be readily apparent that the goals are achievable. This will happen through joint planning and execution of an agreedupon project plan that results in that achievement. It is up to each partner to ensure that they have the resources to execute that project plan on schedule and on budget. As there will always be unplanned events and issues, there must also be ongoing, open communications throughout the life of the sponsorship or partnership. This way, surprises are avoided and issues can be dealt with before they become problems.

2. Risks and rewards must be real and shared. Members of a sponsorship or partnership should share risks and rewards in proportion to the role they hold. Furthermore, the rewards must be seen to be real rewards to all the members. Step into the other members' shoes and look at what you're offering. Does it clearly bring value to the other organizations in the arrangement? If so, how? If not, what can be done to address that disparity? Sponsorships and partnerships should not take advantage of any one sponsor or partner by allocating risks or rewards disproportionately to their contributions. Rewards realized by members of the sponsorship or partnership should be proportionally shared by all the members.

3. Defined time. A sponsorship or partnership is for a defined amount of time and should not be assumed to be ongoing. Regular reviews of how well the sponsorship or partnership is working for the partners must be conducted and decisions made on the basis of those results. It might be that the landscape is changing and the benefits are no longer as meaningful, or there are alternatives now available that provide better benefits for on of the members. Maintaining a sponsorship or partnership past its useful life will only result in the disintegration of the overall relationship.

4. Write it down. Organizations merge, are acquired and sold, people change jobs, and people change responsibilities. Any sponsorship or partnership should have a written agreement outlining the elements above. Once finalized, it should be signed by an appropriate person representing each member organization. That way, when things do change, there is a reference point and the arrangement is more likely to survive any of these precipitous events.

\section{The sponsorships and partnerships needed for tomorrow}

Successful sponsorships and partnerships are a necessary part our landscape today. The world of information and knowledge has become too large, exists in too many silos, and is far too complex. "Competition, collaboration, and cooperation" defines the only path possible for navigating the landscape successfully. As the president of a company in the library automation marketplace, I continue to seek out opportunities that uniquely position our company to effectively maintain success in the marketplace and to provide value for our customers and thus our company. I believe libraries need to seek the same opportunities for their organizations.

Continued on page 7

Carl Grant (carl.grant@exlibrisgroup.com) is President of Ex Libris North America, Des Plaines, Illinois. 
People forget, but paper, the scroll, the codex, and later the book were all major technological leaps, not to mention the printing press and moveable type. . . . There is so much potential for using technology to equalize access to information, regardless of how much money you have, what language you speak, or where you live.

Big ideas, enthusiasm, and hope for the profession, in addition to practical technology-focused information await the reader. Enjoy the issue, and congratulations to the winner and all the finalists!

\section{Note}

1. All quotations are taken with permission from private e-mail correspondence.

\section{A Partnership for Creating Successful Partnerships continued from page 5}

Looking ahead, it seems clear that the pace of change in today's environment will only continue to accelerate; thus the need for us to quickly form and dissolve key sponsorships and partnerships that will result in the successful fostering and implementation of new ideas, the currency of a vibrant profession.

The next challenge is to realize that many of the key sponsorship and partnerships that need to be formed are not just with traditional organizations in this profession. Tomorrow's sponsorships and partnership will be with those organizations that will benefit from the expertise of libraries and their suppliers while in return helping to develop or provide the new funding opportunities and means and places for disseminating access to their expertise and resources. Likely organizations would be those in the fields of education, publishing, content creation and management, and social and community Webbased software.

To summarize, we at Ex Libris believe in sponsorships and partnerships. We believe they're important and should be used in advancing our profession and organizations. From long experience we also have learned there are right ways and wrong ways to implement these tools, and I've shared thoughts on how to make them work for all the parties involved. Again, I thank Marc for his receptiveness to this discussion and my even deeper appreciation for trying to address the issues. It's serves as an excellent example of what I discussed above.

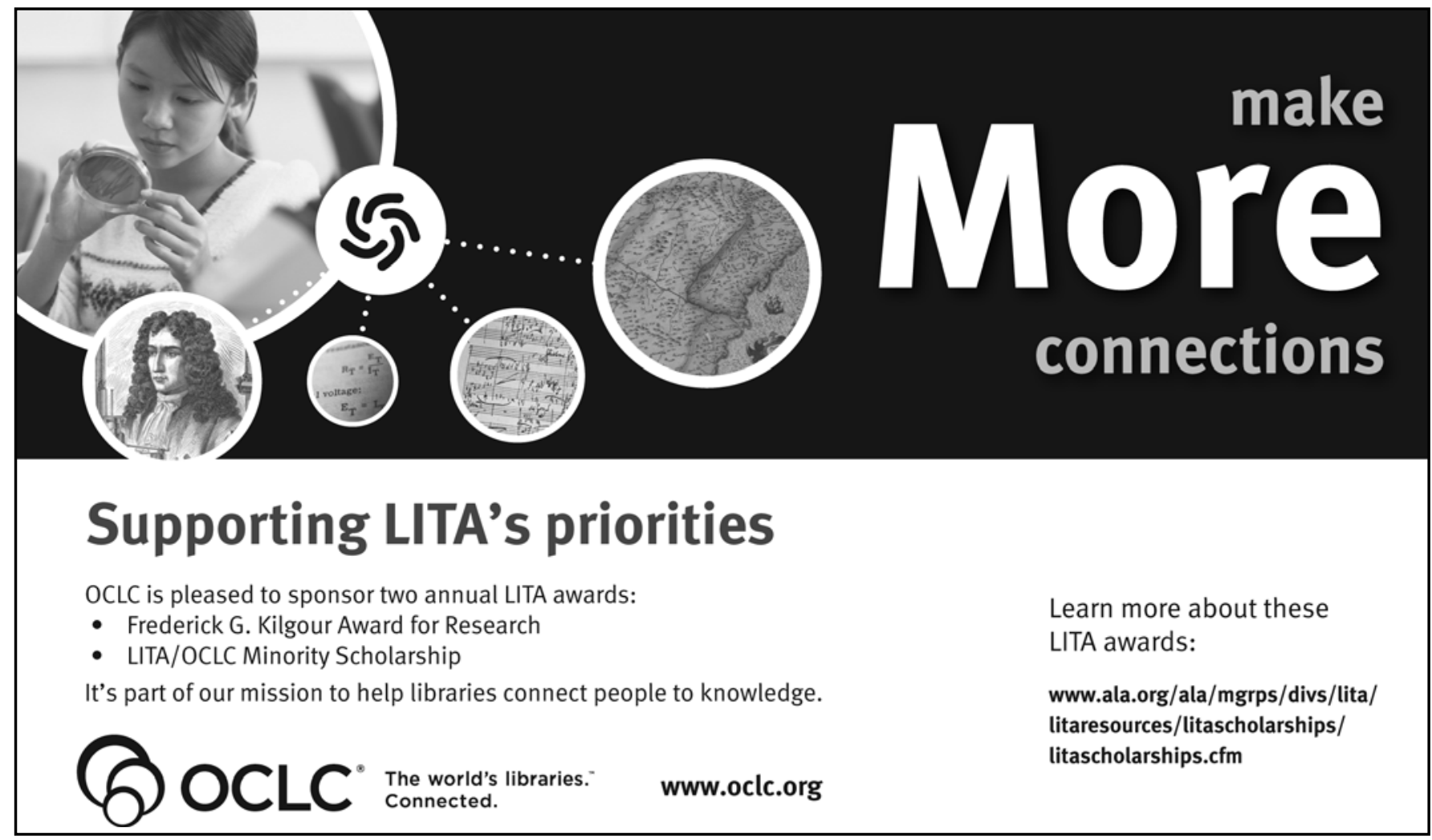

